\title{
Erratum to: Structural and optical properties of Na doped ZnO nanocrystalline thin films synthesized using sol-gel spin coating technique
}

\author{
Shang-Hsuan Wu $\cdot$ Sanjeev Kumar $\cdot$ R. Thangavel $\cdot$ \\ Shien-Uang Jen $\cdot$ Wei-Chun Cheng $\cdot$ Y. C. Chang
}

Published online: 20 May 2014

(C) Springer Science+Business Media New York 2014

\section{Erratum to: J Sol-Gel Sci Technol (2013) 67:50-55 DOI 10.1007/s10971-013-3049-y}

The original publication of this article was submitted and published without the names of four co-authors, Shang-Hsuan Wu, Shien-Uang Jen, Wei-Chun Cheng, Y. C. Chang, in the author group. This has been corrected with this erratum.

Also, the authors would like to update the acknowledgments section which is given below.

\section{Acknowledgments}

This research was supported by University Grants Commission (UGC), Govt. of India, New Delhi, for financial assistance through a minor research project [Ref. No.
39-987/2010 (SR)]. We are also very thankful to Research Centre for Applied Sciences, Academia Sinica, Taipei, Taiwan, for providing characterization facilities. Dr. Thangavel is also thankful to Research Centre for Applied Sciences, Academia Sinica, Taipei, Taiwan, for providing financial support.

In the original publication, there was an error in the caption of Fig. 3. The corrected version of the caption is given below.

Fig. 3 a Raman spectra of $\mathrm{Na}$ doped $\mathrm{ZnO}$ thin films annealed at $500{ }^{\circ} \mathrm{C}$. b Polarized Raman spectra of $\mathrm{Na}$ doped $\mathrm{ZnO}$ thin films with the incident light parallel (instead of perpendicular) to the films. c Polarized Raman spectra of $\mathrm{Na}$ doped $\mathrm{ZnO}$ thin films with the incident light perpendicular (instead of parallel) to the films

The online version of the original article can be found under doi:10.1007/s10971-013-3049-y.

S.-H. Wu · Y. C. Chang

Research Centre for Applied Sciences, Academia Sinica,

Taipei 11529, Taiwan

S. Kumar $(\bowtie)$

University College of Engineering, Punjabi University,

Patiala 147002, India

e-mail: sanjeevace_phy@yahoo.co.in

R. Thangavel

Department of Applied Physics, Indian School of Mines,

Dhanbad 826 004, India

S.-U. Jen

Institute of Physics, Academia Sinica, Taipei 11529, Taiwan

W.-C. Cheng

National Taiwan University of Science and Technology,

Taipei 106, Taiwan 